\title{
Desertification risk assessment in southern Mediterranean areas
}

\author{
M. Greco, D. Mirauda, G. Squicciarino, and V. Telesca \\ CIMA, Department of Environmental Engineering and Physics, Basilicata University, Potenza, Italy \\ Received: 14 November 2004 - Revised: 18 April 2005 - Accepted: 18 April 2005 - Published: 11 July 2005
}

\begin{abstract}
The paper deals some important aspects concerning the study of desertification phenomenon that has significantly interested all European countries of the Mediterranean basin in the last decades. The territorial sensibility, qualitatively and/or quantitatively, of the risk related to the desertification processes has been valued as grade of susceptibility to the phenomenon in the study area, with respect to the hydraulic and hydrologic conditioning factors. The methodological approach followed is based on the classification of desertification indicators by means of a suitable conceptual model applied to the study area in Basilicata region. The classical desertification indexes have been evaluate referring to the study area generating temporal informative map. To achieve such objective, the historical series of temperatures and rainfall of several gauge-stations have been analysed, and the first results show an increasing trend for the temperature in last years, according to the global scale. An increase of aridity and erosion index values is, also, outlined by the collected data with slight reductions at higher altitudes.
\end{abstract}

\section{Introduction}

The phenomenon of desertification has assumed now the feature of a global problem, although with different characteristics in distinct economic, social and environmental contexts. The need of contrasting desertification is largely recognized not only in the areas with large desert zones, but also in the northern countries of the world, in particular the Mediterranean ones, involved in this phenomenon both directly, for degradation processes of the territory, and indirectly, for the repercussions of socio-economic imbalances in the emergent countries. The lack of water and the irrational management of natural resources, at productive and settling ends, such as the increased tendency to leave rural areas, are the main causes of desertification processes, or better of progressive

Correspondence to: M. Greco

(mgreco@unibas.it) reduction of the soil surface layer and its producing capacity loss. The concept that the soil degradation occurs both for climatic and, more and more, for anthropic factors has been consolidated.

The most recent researches disclose as climatic variation can make the existing desertification processes worsen or cause trigger conditions. Let's think to an increasing of aridity conditions and/or to a larger frequency of droughty phenomena and/or to an increase of intense rain that, above all on poor as vegetated soil, can cause a high and rapid ground degradation, for the mechanical removal of its fertile portion. "Human" activities followed this one, together with the exploitation of upland and wooden areas for pasturage in a careless and irrational way without an adequate planning constituting another disequilibrium element. Population concentration in the coastal zones and the intensive agrarian utilization in the same territories determine water requirements that, often for a long period of the year, exceed the real availabilities. Consequently the excessive extraction from coastal aquifers often determines intrusion phenomena of sea water, that lead to increase even more the desertification risk, linked, in that case, to salting effects.

Even though continuous studies for the diffusion control of areas at desertification risk are going on, around the $70 \%$ of the barren grounds used in agriculture is interested by desertification process. Also in the areas with sufficient water for the irrigation, the phenomenon is improving in a significant way: the $30 \%$ of the irrigation water at worldwide level shows a marked soil degradation, while in Europe the percentage is around to $16 \%$. In this way, the present contribution is addressed to the pressure state assessment of Lucanian territory through the reconstruction of the vulnerability thematic maps of different periods. The critical state is calculated by the value assumed by hydraulic and hydrologic indexes representing the process. In particular, with the data analysis of the Lucanian Agency of Development and Innovation in Agriculture (ALSIA) and in the period between 1999 and 2003, the indicators have been valued and the models have been developed, both on aggregate index base and on 
Table 1. Classification of the climatic zones according to the rainfall index.

\begin{tabular}{ll}
\hline Values of $I_{P}$ & Risk level \\
\hline$<280(\mathrm{~mm})$ & arid and semi-arido \\
$280 \div 650(\mathrm{~mm})$ & dry sub-humid \\
$>650(\mathrm{~mm})$ & Humid and hyper-humid \\
\hline
\end{tabular}

disaggregate parameter base, suitable to give a support to the medium term provisional analysis of the studying process. It is important to underline that analysis has been effected using historical series reported to a brief period of observation because of the not complete availability of all data, reported to every climatic parameter, necessary for the elaboration of aggregated indexes that will be considerer later in the paper. Also, being evident that the climatic variables are not correlated to bashful with the recorded courses in the long period, it is necessary to notice that the principal intent of this job has been to make a test of a methodology, following described, respect to the deducible information from the available historical series, apart from the analysis of the evolutionary trends of the selected components, in this phase.

\section{Study methodology}

The performed analysis is based on the use of the state, pressure, impact indicators methodology and, in particular, the hydraulic-hydrologic indexes and the soil ones have been valued (Greco et al., 2003).

It was reached, therefore, the draft valuation of the vulnerability to the desertification risk of the territory examined, giving a first cognitive level to use as work basis propaedeutic to the integration of other indices representing the phenomenon, or better suggesting provisional quantities models that allow the definition of the indicators themselves.

Three different indices have been used, reflecting the territorial system state with regard to the acting climatic stresses. In particular:

- rainfall index;

- aridity index;

- ratio SAU/ST.

The rainfall index is a typically hydrologic index with the double function of considering the rain as one of the main erosive soil agent and, consequently, giving the contribution to the degradation of it, and, on the other hand, of contributing to the vegetation growth.

Three rainfall groups have been identified for this index, considering the rain values accumulated in the space of one year, to which a higher risk is associated when the rainfall decreases.

Unlike the previous one, the aridity index considers the soil because it is calculated as the ratio between the annual
Table 2. Classification of the climatic zones according to the aridity index.

\begin{tabular}{ll}
\hline Values of $I_{a}$ & Definition of the climatic zones \\
\hline$<0.5$ & arid and semi-arid \\
$0.5 \div 0.65$ & dry sub-humid \\
$>0.65$ & Humid and hyper-humid \\
\hline
\end{tabular}

average precipitations, $P$, and the potential annual average evapo-transpiration, ETP, and so it considers the average water availability in the soil essential for the preservation of the vegetal species.

Three groups corresponding to definite climatic zones have been identified for both indices to which a different value has been assigned (Tables 1 and 2).

The ratio Farm Surface Used (SAU)/Total Territorial Surface (ST), finally, gives an indication of the part of the territory really assigned to productive farm activities compared with the total territorial surface and so of the real pressure state both on the territory and on the soil in regard to anthropic activities against the cultivation tendency of the area.

In fact, according to the definition of the ISTAT, the agrarian surface used is considered as the totality of the sow able land surfaces, permanent mead owed surfaces, pasture-land surfaces and agrarian wooden cultivation, kitchen-gardens and fruit chestnut grove. Although the index is mostly socioeconomic, its evolution in time can give indications about the impact exercised by the farms on the environment, above all in terms of soil removed to agrarian use, agriculture extensive or abandonment of marginal areas.

A decrease of the ratio in upland areas is generally interpreted in the negative because it is correlated to a progressive abandonment of "marginal" areas, main cause of soil erosion phenomena and hydro geological risk.

\section{Study area and environmental conditions}

The region of Basilicata is considered as one of the most threatened areas of Italy as far as the phenomenon of desertification is concerned. This is mainly due to climactic changes and to the widespread degradation of the territory resulting from hydro geological instability, woodland fires, and more generally to an ever growing misuse of the land by man.

In particular the most affected areas of this phenomenon are the Ionian alluvial plain and the south-eastern territories characterised by their plio-pleistocene clays.

The former, deriving from the expansion of the region's rivers over coastal deposits left by the sea's regression and now representing the main agricultural area, is subject to important and periodical salting process which in recent years have become more frequent. Although it is not possible to quantify, with great precision, the areas affected by this process or even describe the intensity, the limited fertility of the 


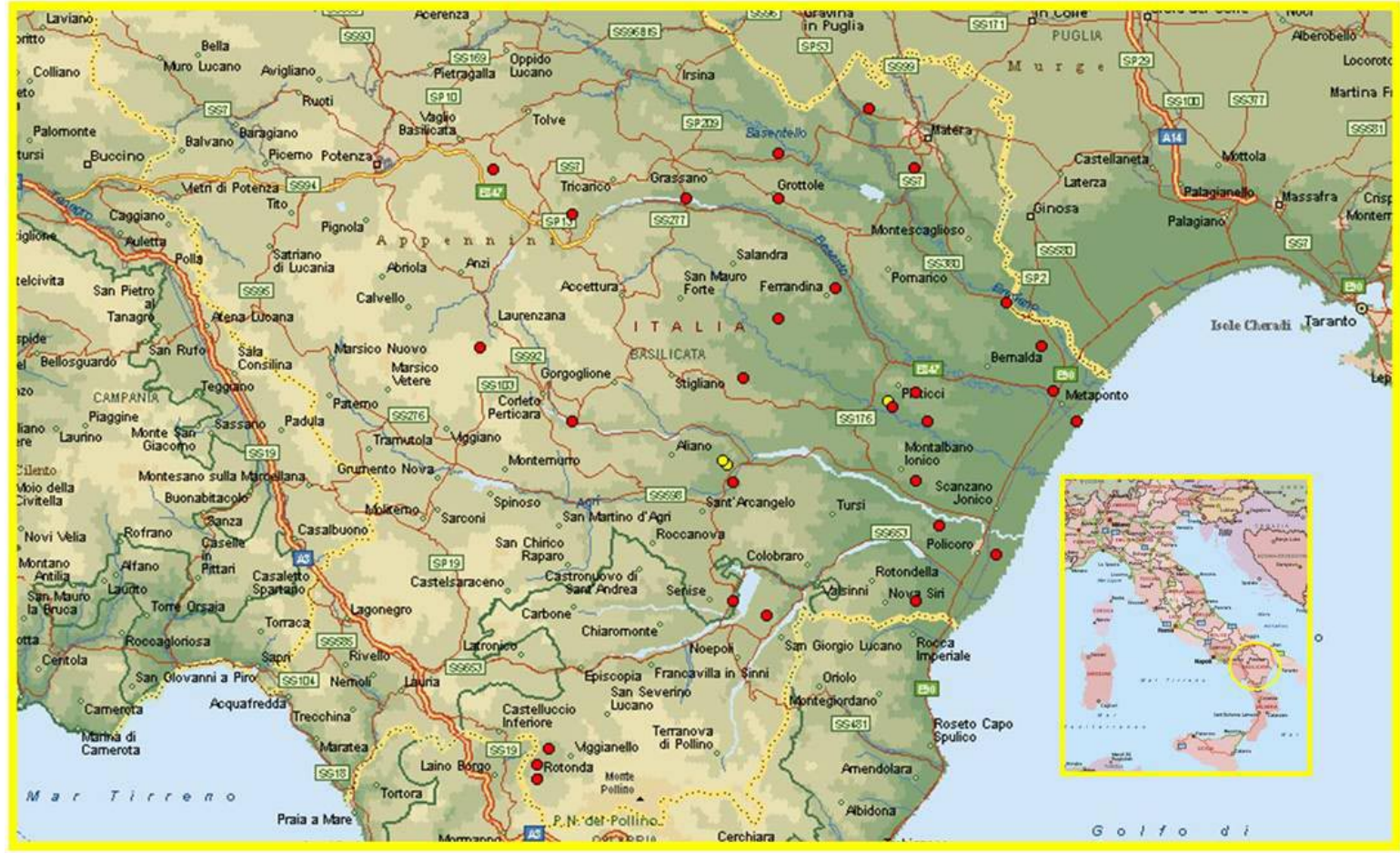

Fig. 1. The study area.

land for agricultural purposes is particularly evident in some areas which were studied. This is due to several contributory factors: the production of erosive materials deriving from marine terraces above the plains which, due to the pedogenetic substrate (plio-pleistocene bluish-grey clays), are rich in soluble salts, and particularly in sodium, sea water infiltration and finally the soil pattern which, if very fine, may result in a deposit of salt along the profile.

These areas are locally defined as "burned land" and can be readily found along the entire coastline from Policoro to Scanzano and up as far as Metaponto and also spread inland for about $1 \mathrm{~km}$ covering an area of $4000 \mathrm{ha}$. The irrigation waters, deriving from the local Consorzio di Bonifica (local water supply) are of a high quality, while the quantity of such water obtained from local wells is very low, as well as being dangerous due to its high salt content (Ministero dell'Ambiente, 1999).

Plio-pleistocene clay areas also tend to be very hard as is the case in about 200000 ha of territory to the south-east of the region. However, these problems are in fact of another nature: the widespread formation of gullies represent a significant index of the high level of land degradation and, consequently, a continuous and progressive increasing of territorial vulnerability. The hot, dry summers cause the surface crust of the south-facing lands and ridges generate a land creeping with the depth of the creeps depending on geographical orientation. It therefore follows that with the aggressive summer and autumn rainstorms an increased surface area is subject to land erosion: from $2 \mathrm{~mm}$ to $20 \mathrm{~mm}$ per year. However, on the other hand, we can also find flat or mildly sloping areas where the intensity of notable desegregation processes is inferior. All this, coupled with the management difficulties arising from the particular morphological features of the area, generate a productive deficiency of these lands: it is for this very reason that these areas are greatly influenced by recent EU directives aimed at extending them and transforming them into productive woodlands (Agenzia Nazionale per la Protezione dell'Ambiente, 2000). The clayey nature of the territory described, is too preponderant to generate a state of aridity constant in time.

It is evident, therefore, that the risk of desertification in Basilicata, due to the intrinsic nature, as well as to the anthropic use of the land is considerably high and that the drawing up of a map, highlighting the area's vulnerable points, represents an essential tool in order to set forth a strategic plan for productive assets and for the establishment of infrastructures within the region.

The study area has interested the zone between the Ionian coast and the hills of Matera area of Basilicata in the territory of Tursi, Montalbano Ionico, Pisticci, Craco, Aliano, Ferrandina (low and middle hills of Matera area), San Mauro Forte, Stigliano, Cirigliano, Gorgoglione (high hills of Matera area) and Guardia Perticara in the province of Potenza as showed in the Fig. 1 covering almost the whole of Lucanian basins. 

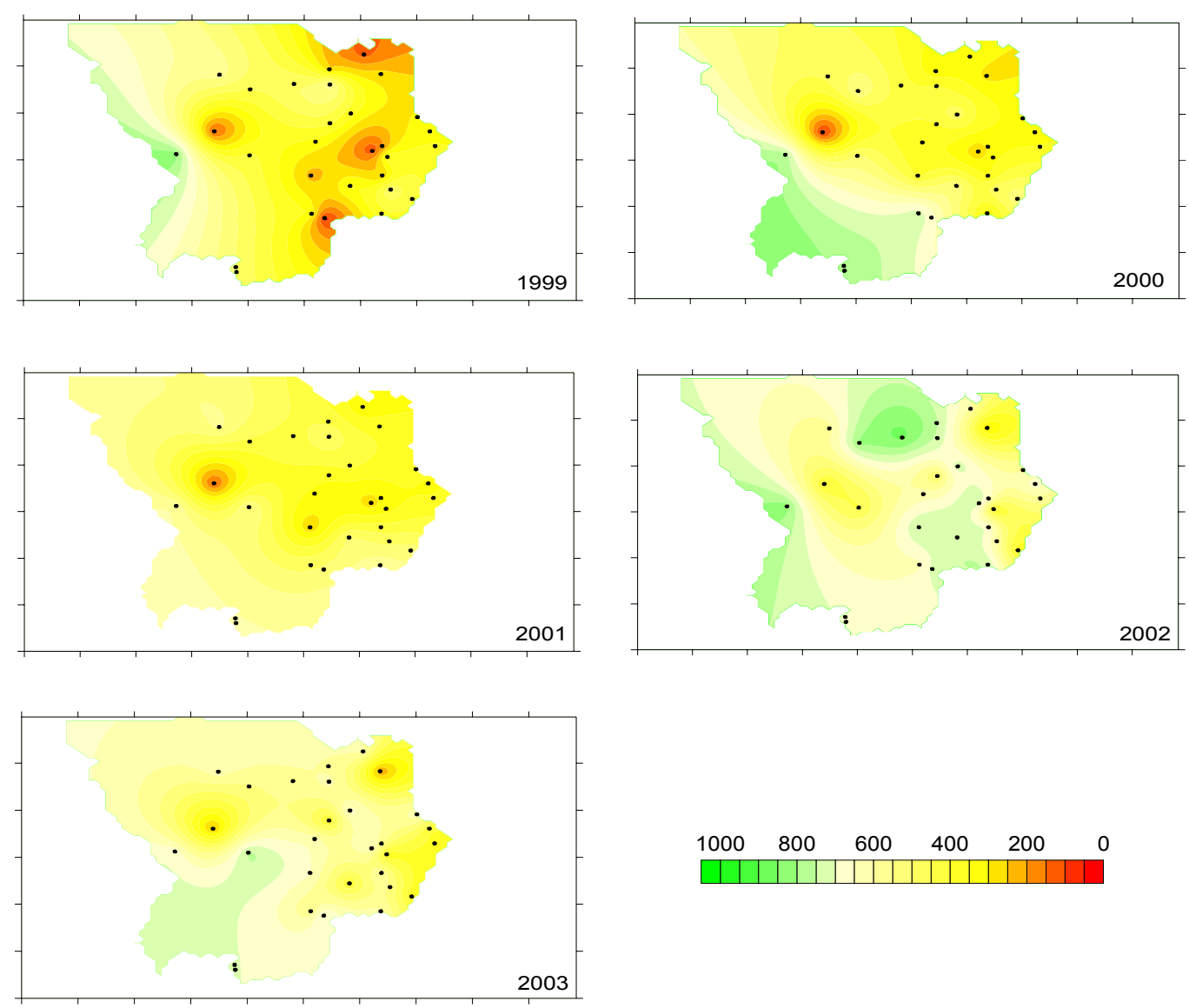

Fig. 2. Spatial distribution of the rainfall index by 1999 to 2003.

\section{Data analysis and first results}

The processing on the select indicators has been performed with reference to the data obtained by the meteorological gauge-stations of ALSIA, distributed on the whole Lucanian territory. In particular, among the thirty nine telemetry control units, the twenty nine of the south-eastern part of the region, corresponding to the whole study area, have been selected.

Data about rain, temperature and relative humidity measurements available in time format, for this work, have been aggregate on a daily basis and, successively, on an annually one. The space distribution and the rainfall index variation, relative to the period of observation 1999-2003, are showed in the Fig. 2 and underline, excluding the year 2002, low annual rainfalls on the whole studying territory. In fact, altogether, rainfall index values around $400-450 \mathrm{~mm}$ have been observed and, for this reason, they place the study areas in the middle-high range of risk.

Figure 3 refers to the aridity index for the same years showing values markedly lower than 0,5 and putting the areas in the zone corresponding to the arid and semi-arid zones. The reading of temporal vulnerability maps of the two indices allows to draw useful information about the pressure state to which the Lucanian territory is subjected and, in par-

ticular, the south-eastern part of the region. The observed rainfall shortage, in fact, versus an evident stability of the aridity index on middle-high values, states, in a more accurate way, what emerges from the analyses conduced on a national scale underlining a tendential increase of desertification risks of the territory in answer to the imposed aridity conditions to which the area has been subjected.

Finally, the information derivable from the spatial distribution of the ratio SAU/ST, even if averaged on the long term, shows a high degree of utilization of the soil for agrarian use with percentages between the $70 \%-85 \%$, strengthening the positions derived from hydrologic indices analysis, showing the presence and the possible increase of a high vulnerability state of territory, concause of the climatic and anthrophic components.

\section{Conclusions}

The study of some physical-climatic and hydrologic indicators, and their following comparison in different times, allow a valuation of the vulnerability degree of Basilicata Region. The analysis of the rainfall index maps that registers the rainfall shortage in the last years, the aridity index value that puts the territory in an arid or semi-arid area and the high 

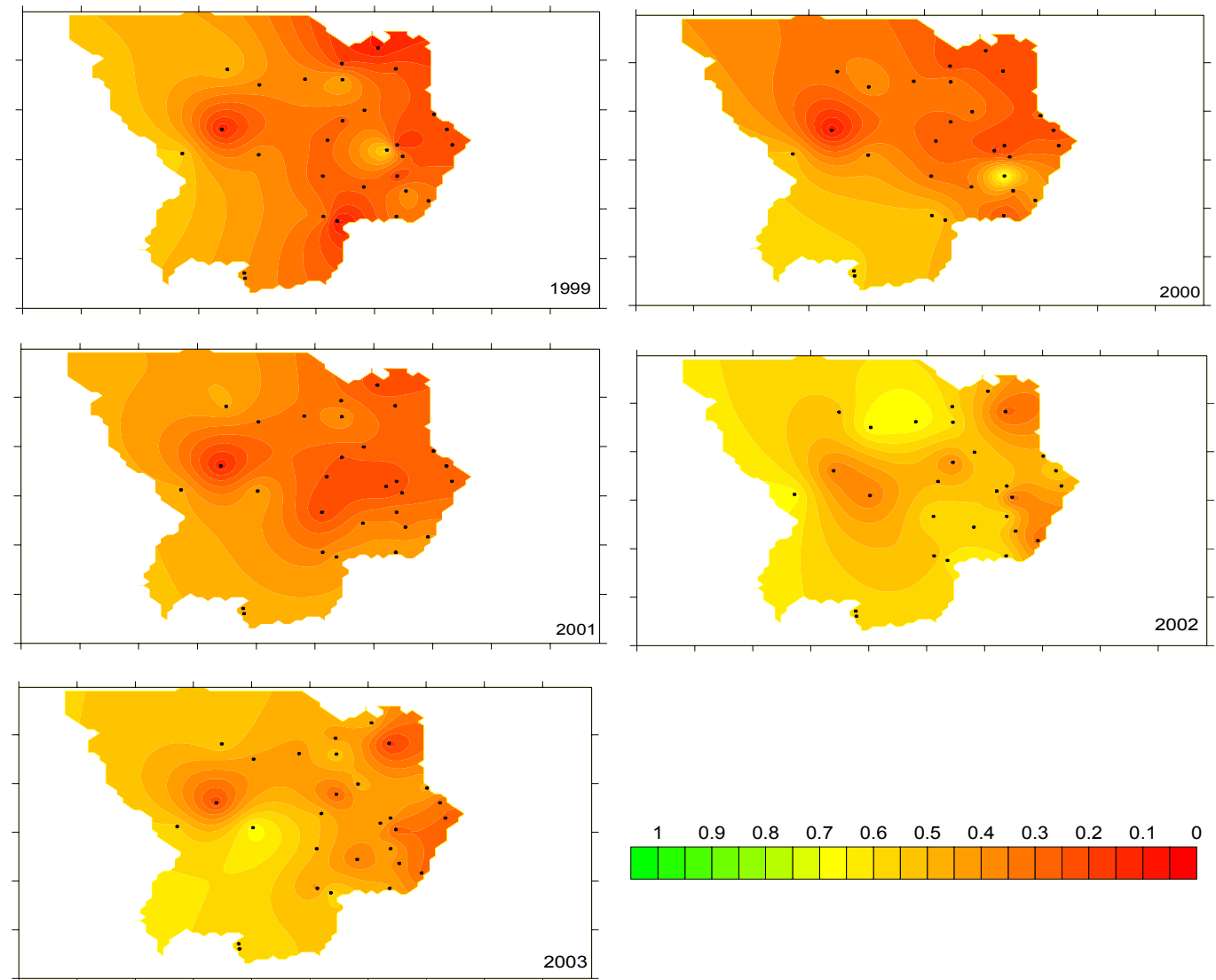

Fig. 3. Spatial distribution of the aridity index by 1999 to 2003.

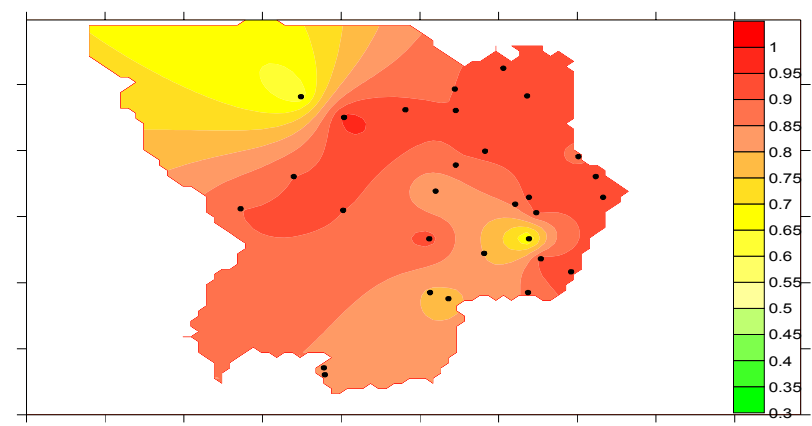

Edited by: L. Ferraris

Reviewed by: anonymous referees

\section{References}

Agenzia Nazionale per la Protezione dell'Ambiente, ANPA: Sviluppo di indicatori per il suolo e siti contaminati, Roma, 2000.

Greco, M., Telesca, V., and Squicciarino, G. :Applicazione di un modello concettuale DTPSIR per lo studio della desertificazione del territorio lucano, Documenti del territorio, 52, 2003.

Ministero dell'Ambiente: Comunicazione nazionale per la lotta alla siccità ed alla desertificazione, Roma, 1999.

Fig. 4. Ratio SAU/ST.

ratio SAU/ST have showed an increase of the sensitive areas toward aridity and desertification phenomena. The results obtained have allowed to make a draft valuation of the vulnerability state to the desertification of the studying territory, reaching a first cognitive level to expand in future introducing other indices representative of the phenomenon. 